\title{
Effect of ocean current on the dead-reckoning estimation of 3-D dive paths of emperor penguins
}

\author{
Kozue Shiomi ${ }^{1, *}$, Katsufumi Sato ${ }^{2}$, Hiromichi Mitamura ${ }^{1}$, Nobuaki Arai ${ }^{1}$, \\ Yasuhiko Naito ${ }^{3}$, Paul J. Ponganis ${ }^{4}$ \\ ${ }^{1}$ Department of Social Informatics, Graduate School of Informatics, Kyoto University, Kyoto 606-8501, Japan \\ ${ }^{2}$ International Coastal Research Center, Ocean Research Institute, University of Tokyo, 2-106-1 Akahama, Otsuchi, \\ Iwate, 012-1102, Japan \\ ${ }^{3}$ National Institute of Polar Research, 1-9-10, Kaga, Itabashi, Tokyo 173-8515, Japan \\ ${ }^{4}$ Center for Marine Biotechnology and Biomedicine, Scripps Institution of Oceanography, University of California San Diego, \\ La Jolla, California 92093-0204, USA
}

\begin{abstract}
The dead-reckoning technique is a useful method for obtaining 3-D movement data of aquatic animals. However, such positional data include an accumulative error. Understanding the source of the error is important for proper data interpretation. In order to determine whether ocean currents affect dive paths calculated by dead-reckoning, as has previously been hypothesized, we examined the directions of the estimated positions relative to the known real points (error direction) and the relationship between the error direction and the current direction. 3-D dive paths of emperor penguins Aptenodytes forsteri diving at isolated dive holes in eastern McMurdo Sound were reconstructed by dead-reckoning, and the net error and error direction were calculated. The net error correlated positively with the dive duration. The error directions were not distributed uniformly, and the mean error direction tended to be north of the starting point of dives. Because there was a southwardflowing current in eastern McMurdo Sound, the ocean current was likely to affect the calculated dive paths. Therefore, the method of error correction generally used, in which the net error divided by the dive duration is applied to each estimated position, is realistically appropriate, provided that the current does not change significantly during a dive.
\end{abstract}

KEY WORDS: 3-D dive path · Dead-reckoning · Ocean current · Error direction · Emperor penguin . Data logger

Resale or republication not permitted without written consent of the publisher

\section{INTRODUCTION}

The development of time-depth recorders (Kooyman 1968) and satellite telemetry (Stoneburner 1982) makes it possible to access information on the behavior of aquatic animals in remote environments. However, those methods can reveal only 2-D (time-depth or horizontal) movements, while aquatic animals travel and forage underwater in 3-D space. It is essential to obtain 3-D movement data in order to fully interpret their foraging behavior and physiological responses during dives.

Currently, there are 2 methods for reconstructing the 3-D movements of aquatic animals (Wilson et al. 2007): acoustic telemetry (Lagardère et al. 1990) and deadreckoning (Wilson \& Wilson 1988). With these methods, some significant insights about diving animals, such as habitat preference (e.g. Hindell et al. 2002) and the interaction between behavior and prey distribution (e.g. Mitani et al. 2004) have been obtained. Acoustic telemetry necessitates that receivers are within a few hundred meters of the animal to be tracked; hence, data on fast and wide-ranging species are difficult to obtain with this method (Wilson et al. 2007). The dead-reckoning technique overcomes this problem; it requires data on speed, heading, and change in depth (or pitch angle), with which the locomotion vectors per measurement interval 
are calculated. By integrating those vectors, 3-D movements of the animals can be reconstructed. Temporally finely resolved, regular, sequential positional data can be obtained by dead-reckoning without the constraint of the measuring range.

However, dive paths obtained by dead-reckoning necessarily include an accumulative error, due to the lack of reference points underwater (Mitani et al. 2003, Wilson et al. 2007). Generally, the net error is considered to be the distance between the known point and the corresponding point estimated by dead-reckoning. In order to correct the estimated positional data, the net error is divided by the time elapsed between the subsequent known positions, and the fraction is applied to each estimated position (Mitani et al. 2003, Wilson et al. 2007). This method assumes a constant linear drift, accumulating the error in amplitude and direction over time.

Wilson et al. (1991) described that positional fixes estimated by dead-reckoning become more inaccurate with time and that the greatest source of inaccuracy is ocean current. If ocean current actually affects the dive paths, it is hypothesized that the directions of the estimated points relative to the real positions (error direction) will not be uniformly distributed, but will be opposite to the direction of the prevailing current. This is because dive paths calculated by dead-reckoning do not reflect passive transport by external factors.

In the present study, using emperor penguins Aptenodytes forsteri, we aimed: (1) to confirm whether the error directions of the dive paths estimated by deadreckoning are distributed in a certain direction, and, if so, (2) to examine the relationship between the error directions and the current direction.

\section{MATERIALS AND METHODS}

We considered 'Penguin Ranch' in McMurdo Sound, Antarctica $\left(77^{\circ} 43^{\prime} \mathrm{S}, 166^{\circ} 07^{\prime} \mathrm{E}\right.$ ) to be suitable as the experimental site, where emperor penguins Aptenodytes forsteri dived in and out of the sea through only 2 isolated ice holes, $1.2 \mathrm{~m}$ diameter wide and $8 \mathrm{~m}$ apart, drilled through the 2.3 to $2.5 \mathrm{~m}$ thick ice and inside a corral (see Sato et al. 2005). Under these conditions, the starting and ending points of dives were known, so the characteristics of the error by dead-reckoning could be examined. The penguins exited the sea using either hole, even if seals occasionally occupied 1 ice hole for resting.

Three emperor penguins (A, B, C), captured near the sea ice edge of eastern McMurdo Sound, were maintained in the corral. A southward-flowing current was found to predominate near our site $\left(77^{\circ} 49^{\prime} \mathrm{S}, 166^{\circ} 07^{\prime} \mathrm{E}\right)$ by Barry \& Dayton (1988). A data logger (W1000L3MPD3GT: $26 \mathrm{~mm}$ diameter, $174 \mathrm{~mm}$ in length, $120 \mathrm{~g}$ weight in air; Little Leonardo) was attached to the back of each penguin 1 to 3 times with waterproof tape (Tesa) and instant glue (Loctite, Henkel) following Wilson et al. (1997). They foraged daily beneath the sea ice through the isolated dive holes, and the data logger was retrieved 38.0 to $60.4 \mathrm{~h}$ after attachment (Table 1).

The data logger recorded swimming speed, depth, ambient temperature, and 3-D (longitudinal, lateral, dorso-ventral) geomagnetism at $1 \mathrm{~s}$ intervals, and 3-D acceleration at $1 / 16$ or $1 / 32 \mathrm{~s}$ intervals with a memory of $512 \mathrm{Mb}$. The acceleration sensor of the data logger measured both dynamic acceleration by propulsive activity and static acceleration by gravity (Tanaka et al. 2001, Sato et al. 2003). Gravitational acceleration data were extracted from the acceleration data with a low-pass filter (IFDL Version 4.0; Wave Metrics) (Tanaka et al. 2001). The dynamic acceleration data were not used in the present study. The low-pass filter characteristics for emperor penguins were $<0.5 \mathrm{~Hz}$ for longitudinal and dorso-ventral acceleration and from 0.6 to $0.7 \mathrm{~Hz}$ for lateral acceleration.

The speed sensor of the logger consisted of an external propeller and a propeller rotation counter. It has been verified experimentally that the rotations of the propeller per second (rps) are proportional to swim-

Table 1. Aptenodytes forsteri. Data from the deployments of data loggers on 3 individuals (A, B, C). The dive characteristics in each deployment are presented as mean values $( \pm \mathrm{SD})$, and the maximum value of each parameter is in parentheses. Dive depth and duration were calculated for all dives; horizontal distance was calculated for dives used for the error analysis (see 'Materials and methods')

\begin{tabular}{|lccccccc|}
\hline $\begin{array}{l}\text { Deploy- } \\
\text { ment }\end{array}$ & $\begin{array}{c}\text { Deployment } \\
\text { duration } \\
(\mathrm{h})\end{array}$ & $\begin{array}{c}\text { Total no. } \\
\text { of dives } \\
(\mathrm{n})\end{array}$ & $\begin{array}{c}\text { Number of } \\
\text { dive paths } \\
(\mathrm{n})\end{array}$ & $\begin{array}{c}\text { Number of dive } \\
\text { paths analyzed } \\
(\mathrm{n})\end{array}$ & $\begin{array}{c}\text { Dive } \\
\text { depth } \\
(\mathrm{m})\end{array}$ & $\begin{array}{c}\text { Dive } \\
\text { duration } \\
(\mathrm{s})\end{array}$ & $\begin{array}{c}\text { Horizontal } \\
\text { distance } \\
(\mathrm{m})\end{array}$ \\
\hline $\mathrm{A}-1$ & 50.3 & 175 & 164 & 54 & $20.7 \pm 15.4(80.3)$ & $216.3 \pm 229.2(927)$ & $435.6 \pm 213.2(908.3)$ \\
A-2 & 48.3 & 86 & 73 & 41 & $26.8 \pm 16.4(52.0)$ & $361.5 \pm 297.2(1187)$ & $529.9 \pm 226.4(1190.2)$ \\
B-1 & 38.0 & 131 & 102 & 31 & $29.0 \pm 22.9(95.8)$ & $237.1 \pm 267.7(899)$ & $458.3 \pm 171.6(699.3)$ \\
B-2 & 52.5 & 119 & 88 & 37 & $30.7 \pm 21.6(82.3)$ & $307.4 \pm 338.9(1074)$ & $569.1 \pm 304.0(1023.4)$ \\
B-3 & 60.4 & 134 & 118 & 47 & $27.5 \pm 18.0(70.5)$ & $266.5 \pm 311.6(1148)$ & $411.9 \pm 276.1(1032.9)$ \\
C & 55.6 & 133 & 110 & 35 & $26.3 \pm 19.0(69.8)$ & $327.7 \pm 379.0(1329)$ & $600.0 \pm 347.1(1210.9)$ \\
Total & 305.1 & 778 & 655 & 245 & & & \\
\hline
\end{tabular}


ming speeds relative to water with a high coefficient of determination (>0.9) (Tanaka et al. 2001, Sato et al. 2007). In order to obtain the constant of proportion, $b$, for converting the number of propeller rotations to the swimming speed, the estimated vertical rate, $R_{t}$, was first calculated at a given time, $t$, with the number of propeller rotations per second, $N_{t}$, and the angle of the penguins' longitudinal axis relative to the horizontal plane, $\theta_{t}$ using Eq. (1). $\theta_{t}$ was calculated from gravitational acceleration and the attachment angles of the logger following Sato et al. (2003):

$$
R_{t}=b \times N_{t} \times \sin \theta_{t}
$$

The estimated depth profile was then calculated by adding $R_{t}$ sequentially from the starting time to the ending time of a dive. The optimal value for $b$ was determined by repeating the calculation of the estimated dive profile with several different values of $b$ (Fig. 1). With the optimal value, the estimated depth profile fitted the depth profile measured with the depth sensor well (Fig. 1). This procedure was repeated for 10 dives selected randomly from the dives of each deployment. The average of 10 constants was used for calculating actual swimming speeds. The standard deviations of the constants were $<3 \%$ of the average values. The stall speed of the logger was determined experimentally to be $0.3 \mathrm{~m} \mathrm{~s}^{-1}$ (Tanaka et al. 2001). Speeds below this value were considered indistinguishable from zero.

The heading on the horizontal plane at each time point was determined from the rotation angles of the longitudinal and lateral axes (pitch, roll) and the data

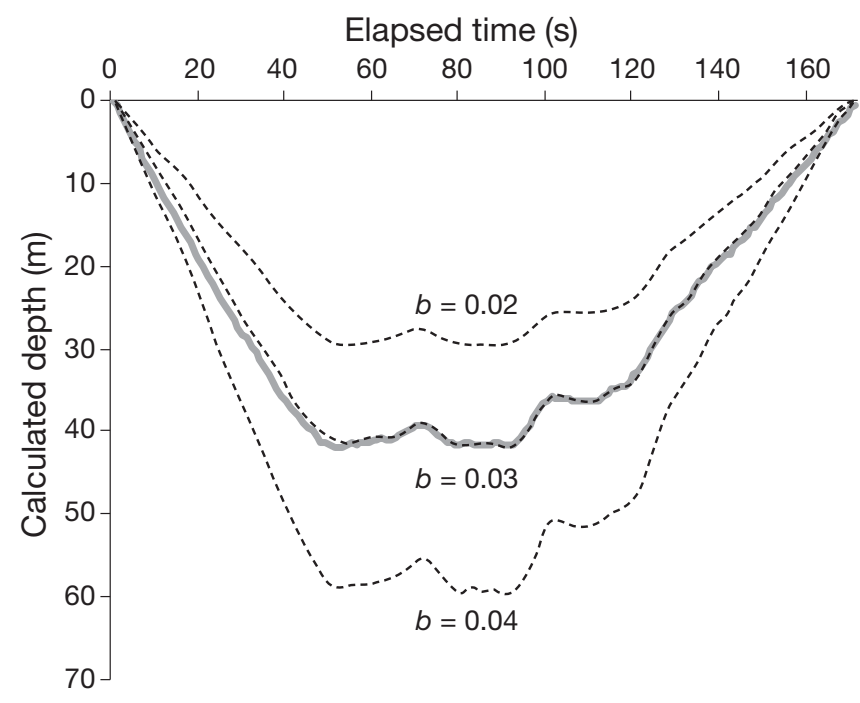

Fig. 1. Aptenodytes forsteri. Comparison of measured depth profile (-) and estimated depth profiles (------) calculated using several values of the constant $b$ for converting the number of propeller rotations per second to the swimming speed. For this dive, 0.03 is appropriate of 3-D geomagnetism (Johnson \& Tyack 2003). Gravitational accelerations along the dorso-ventral axis were always positive, suggesting that the birds did not swim on their backs. Therefore, pitch and roll were calculated to be within $\pm 90^{\circ}$ using 3-D acceleration data (Johnson \& Tyack 2003). Then, the locomotion vector with reference to the fixed frame $\left(x_{t}, y_{t}, z_{t}\right)$, at a given time, $t$, was calculated with the data on heading, $h_{t}$, pitch, $p_{t}$, depth change, $\left(D_{t}-D_{t-1}\right)$, and swimming speed, $V_{t}$, using Eq. (2). The $x$-axis is northward, the $y$-axis is westward, and the $z$-axis is upward (depth presented as negative):

$$
\begin{aligned}
& x_{t}=V_{t} \times \cos \left(p_{t}\right) \times \cos \left(h_{t}+d\right) \\
& y_{t}=-V_{t} \times \cos \left(p_{t}\right) \times \sin \left(h_{t}+d\right) \\
& z_{t}=D_{t}-D_{t-1}
\end{aligned}
$$

where $d$ is the declination of earth's magnetism in this experimental field, $144.8^{\circ}$ (Maus et al. 2005).

Here, one point should be noted: when penguins flap their flippers, the pitch angle changes up and down (Clark \& Bemis 1979). However, with the method we used, changes in pitch of the same frequency as flapping are excluded as dynamic acceleration by the lowpass filter, and the pitches calculated from static acceleration data during stroking are not correct. As a result, headings calculated using the pitch data were likely to include error. Therefore, we replaced the headings recorded during stroke cycles for about $0.77 \mathrm{~s}$ (reflecting the dominant stroke frequency of emperor penguins; Sato et al. 2007) with the preceding heading data.

Finally, the dive path was reconstructed with the locomotion vectors during a dive by employing a deadreckoning principle (Wilson \& Wilson 1988, Mitani et al. 2003).

The distance between the 2 ice holes at 'Penguin Ranch' was $8 \mathrm{~m}$. Though it is unknown which hole the penguins used on entering and exiting the sea for each dive, we considered the ending point of a dive to be consistent with the starting point. Therefore, the net error was calculated as the difference between the starting and ending points of reconstructed dive paths (Mitani et al. 2003, Wilson et al. 2007). In addition, the direction of the estimated ending point relative to the starting point was calculated as the error direction (Mitani 2002), to test whether the directions were distributed opposite to the ocean current direction. The uniformity of the distribution of the error directions during each deployment was examined using a Rayleigh test, and the mean error directions were compared among all deployments using the WatsonWilliams test (Zar 1999, Chap 27).

We considered submergence for $>30 \mathrm{~s}$ to be a dive. The maximum depth during each dive was defined as the dive depth and the distance on the horizontal plane 
between the farthest point and the starting point of a dive as the horizontal distance. Only dives in which the dive depth was $>25 \mathrm{~m}$ and the horizontal distance was $>100 \mathrm{~m}$ were used for the error analysis. We did not consider the other dives to be suitable for the analysis, because the penguins swam tortuously and irregularly near the dive holes during those dives. Results are presented as means ( \pm standard deviation), and the results of tests were assumed to be significant at $\mathrm{p}<0.05$.

\section{RESULTS}

The 3 emperor penguins performed 778 dives during 6 deployments (Table 1). For each deployment, mean dive depth was $20.7 \pm 15.4$ to $30.7 \pm 21.6 \mathrm{~m}$, and mean dive duration was $216.3 \pm 229.2$ to $361.5 \pm 297.2 \mathrm{~s}$ (Table 1). Of all dives, 3-D dive paths of 655 dives were calculated (Table 1). Those of the remaining dives (i.e. 123 dives) could not be reconstructed due to a stall of the propeller measuring the swimming speed. Of all dive paths, 245 dives were $>25 \mathrm{~m}$ in dive depth and $>100 \mathrm{~m}$ in horizontal distance. The birds sometimes moved to distances in excess of $1 \mathrm{~km}$ from the ice hole, $1210.9 \mathrm{~m}$ being the maximum (Table 1 ).

The calculated ending points of the dive paths were always inconsistent with the known starting point as shown in Fig. 2. The mean net error of a dive in each deployment ranged from $113.3 \pm 79.8$ to $215.1 \pm 190.2$ $\mathrm{m}$, and the net error correlated positively with the dive duration (Pearson's correlation coefficient; $r_{\mathrm{C}}=0.64$ to 0.82, p < 0.01; Fig. 3, Table 2). The net error divided by the dive duration, i.e. the error-per-second of a dive, varied between $0.18 \pm 0.09$ and $0.37 \pm 0.15 \mathrm{~m} \mathrm{~s}^{-1}$ for 6 deployments. In all deployments, the directions of the

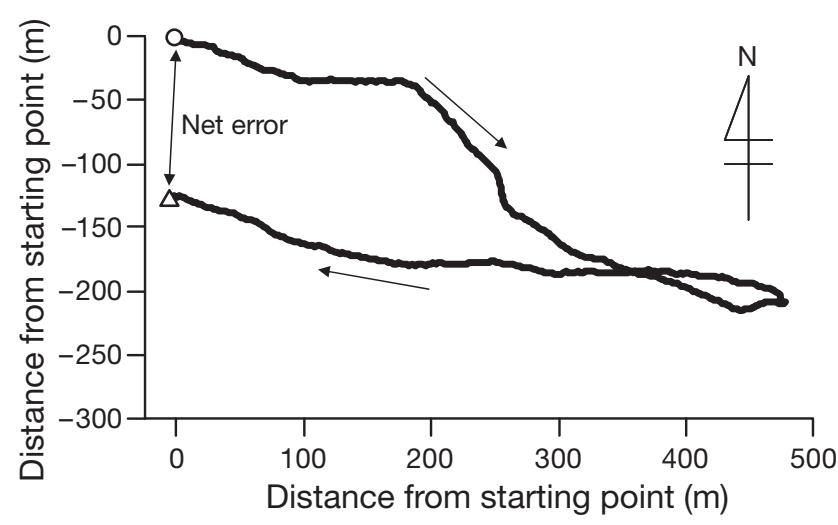

Fig. 2. Aptenodytes forsteri. Overhead view of a dive path calculated by dead-reckoning. Open circle: the coordinate $(0$, 0 ) presents the starting point; open triangle: the estimated ending point of the dive. Note that the $x$-axis is eastward and the $y$-axis is northward. The amplitude of net error in this dive path is displayed by a 2-headed arrow

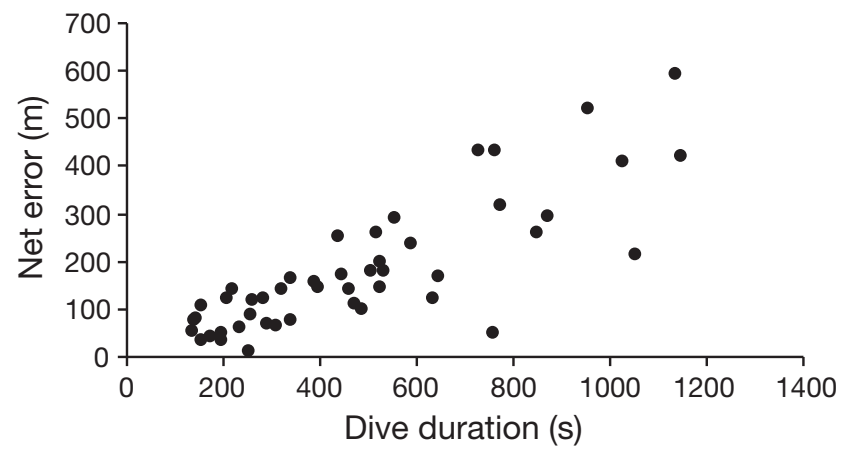

Fig. 3. Aptenodytes forsteri. Relationship between dive duration and net error in a deployment $(\mathrm{B}-3 ; \mathrm{n}=47)$. The correlation coefficient, $r_{\mathrm{C}}$, was 0.82 . Note that only the data of dives in which dive depth was $>25 \mathrm{~m}$ and maximum horizontal distance from the starting point was $>100 \mathrm{~m}$ are displayed (see 'Materials and methods')

ending points relative to the starting point were biased significantly (Fig. 4; Rayleigh test; $\mathrm{p}<0.001, r_{\mathrm{R}}=0.53$ to $0.84)$. Although the mean angles were different between deployments (Watson-Williams test; $\mathrm{p}<0.001$ ), most of the estimated ending points were north relative to the starting points (Fig. 4).

\section{DISCUSSION}

The dive depths and durations of the emperor penguins presented in Table 1 appeared similar to those in previous studies at Penguin Ranch (e.g. Ponganis et al. 2000). We also found that the penguins went to points $>1 \mathrm{~km}$ distant from the ice holes at a maximum (Table 1). This is the first report of 3-D movements of emperor penguins under the fast sea ice.

In a previous study, a positive correlation was found between the dive duration of Weddell seals Leptonychotes weddellii and the distance between the starting and ending points of their dive paths as calculated by dead-reckoning (Mitani et al. 2003). In addition, the distributions of the estimated ending points of the dive paths in each deployment were significantly biased relative to the starting point (Mitani 2002). However, it could not be confirmed that the directions of the estimated ending points represented the error directions, because the free-ranging seals did not necessarily use the same ice hole at the start and end of their dives. In view of this problem, Penguin Ranch, where the animals absolutely returned to the same place, was chosen as our experimental site.

The calculated ending points of the emperor penguin dive paths were always inconsistent with the starting point, as shown in Fig. 2, and the longer the birds dived, the larger the net errors became (Fig. 3, Table 2), as Wilson et al. (1991) suspected. Thus, the 
Table 2. Aptenodytes forsteri. Amplitude of the error in each deployment (mean $\pm \mathrm{SD}$ ) and Pearson's correlation coefficient between the net error and the dive duration. Error-per-second is the net error divided by the dive duration; ${ }^{* *} \mathrm{p}<0.01$

\begin{tabular}{|lccccc|}
\hline $\begin{array}{l}\text { Deploy- } \\
\text { ment }\end{array}$ & $\begin{array}{c}\text { Number of dive } \\
\text { paths for error } \\
\text { analysis (n) }\end{array}$ & $\begin{array}{c}\text { Net } \\
\text { error } \\
(\mathrm{m})\end{array}$ & $\begin{array}{c}\text { Error-per- } \\
\text { second } \\
\left(\mathrm{m} \mathrm{s}^{-1}\right)\end{array}$ & $\begin{array}{c}\text { Correl. } \\
\text { coeff. }\end{array}$ & $\begin{array}{c}\text { Signifi- } \\
\text { cance }\end{array}$ \\
\hline $\mathrm{A}-1$ & 54 & $117.5 \pm 102.5$ & $0.24 \pm 0.14$ & 0.64 & ${ }^{* *}$ \\
$\mathrm{~A}-2$ & 41 & $113.3 \pm 79.8$ & $0.18 \pm 0.09$ & 0.73 & ${ }^{* *}$ \\
$\mathrm{~B}-1$ & 31 & $179.4 \pm 96.4$ & $0.31 \pm 0.13$ & 0.62 & ${ }^{* *}$ \\
$\mathrm{~B}-2$ & 37 & $197.7 \pm 122.6$ & $0.32 \pm 0.10$ & 0.81 & ${ }^{* *}$ \\
$\mathrm{~B}-3$ & 47 & $180.0 \pm 135.9$ & $0.37 \pm 0.15$ & 0.82 & ${ }^{* *}$ \\
C & 35 & $215.1 \pm 190.2$ & $0.28 \pm 0.15$ & 0.81 & ${ }^{* *}$ \\
\hline
\end{tabular}
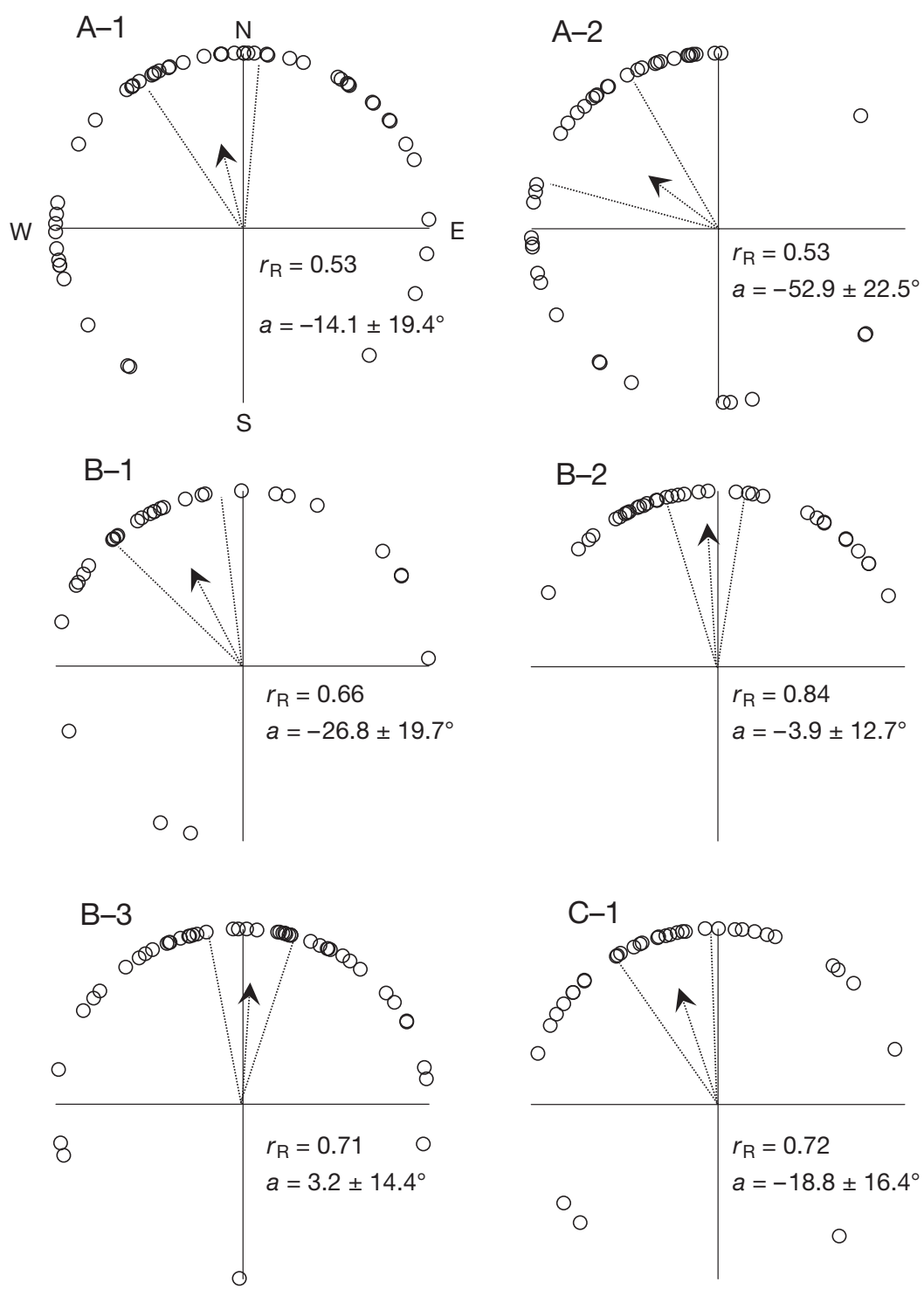

Fig. 4. Aptenodytes forsteri. Distribution of estimated ending point directions for each dive, relative to the starting point. The dashed arrows present the mean vectors; $r_{\mathrm{R}}$ is the length of the mean vector and $a$ is the mean angle. The length of the vector is drawn proportional to the radius of the circle $=1$.

The confidence limit for the mean angle was marked by dashed lines error was incurred in a time-based cumulative manner. Additionally, in all 6 deployments, the distribution of the estimated ending points was biased significantly, and the error directions tended to be north relative to the starting point (Fig. 4). A southward-flowing current was predominate near Penguin Ranch (Barry \& Dayton 1988), and the mean angles of the error directions were close to the major axis of the current identified by principle component analysis (see Fig. 3a in Barry \& Dayton 1988). Those results verified the hypothesis that the points estimated by dead-reckoning deviate towards the opposite of the ocean current direction relative to the real positions. However, it should be noted that the error-per-second values (Table 2) were much larger than the mean current speed $\left(0.076 \mathrm{~m} \mathrm{~s}^{-1}\right.$; Barry \& Dayton 1988). In the present study, the difference could be explained only by the possibility that the current speed in our experimental period was faster than that studied by Barry \& Dayton (1988). In future studies, the current speed and direction should be measured in the experimental site.

Other potential factors that may have caused error include the drift secondary to the centrifugal force when the penguins veered, the inaccuracy of the data used for calculating the dive paths, and the difference between the headings of the attached data logger and the penguins' longitude axis (Wilson et al. 2007). But the direction of the error deriving from those factors is probably variable, depending on the direction of the penguins' movement. Considering that the penguins swam in various directions (Shiomi et al. in press) and that the error direction was biased significantly in all deployments, it seems highly unlikely that those factors were the main cause of error.

Finally, we conclude that the ocean current affected the dive paths calculated by dead-reckoning. Therefore, the method generally used for error compensation could realistically be viable, assuming the effect of the current does not change significantly depending on depth, the animal's body angle, and heading. In free-ranging animals, GPS loggers would be helpful for error correction (Wilson et al. 2007). If the animal moves across different 
layers of current, or if the distances between the subsequent known points are relatively long, measuring the direction and speed of the current in each area is advantageous in order to correct the positional data as accurately as possible.

Acknowledgements. We thank T. K. Stockard, J. U. Meir, Y. Habara, K. V. Ponganis, J. Heil and E. Stockard for their assistance in the field. Comments by Y. Mitani contributed to the improvement of the manuscript. We are also grateful to K. Shimatani for his comments on improving the method of calculating dive paths. This study was made possible by the National Science Foundation (OPP-0229638), grants from the Japan Society for the Promotion of Science (A15255003, A19255001), Sasakawa Scientific Research Grant from The Japan Science Society, Grant-in-Aid for JSPS Fellows (18-2409) and Kyoto University Global COE program on Informatics Education and Research Center for KnowledgeCirculating Society.

\section{LITERATURE CITED}

Barry JP, Dayton PK (1988) Current patterns in McMurdo Sound, Antarctica and their relationship to local biotic communities. Polar Biol 8:367-376

Clark BD, Bemis W (1979) Kinematics of swimming penguins at the Detroit Zoo. J Zool 188:411-428

Hindell MA, Harcourt R, Waas JR, Thompson D (2002) Finescale three-dimensional spatial use by diving, lactating female Weddell seals Leptonychotes weddellii. Mar Ecol Prog Ser 242:275-284

Johnson MP, Tyack PL (2003) A digital acoustic recording tag for measuring the response of wild marine mammals to sound. IEEE J Oceanic Eng 28:3-12

Kooyman GL (1968) An analysis of some behavioral and physiological characteristics related to diving in the Weddell seal. Antarct Res Ser 11:227-261

Lagardère JP, Ducamp JJ, Favre L, Dupin JM, Spèrandio M (1990) A method for the quantitative evaluation of fish movements in salt ponds by acoustic telemetry. J Exp Mar Biol Ecol 141:221-236

Maus S, Macmillan S, Chernova T, Choi S and others (2005) The 10th-generation international geomagnetic reference field. Geophys J Int 161:561-565

Mitani Y (2002) The analysis of three-dimensional diving behavior of Weddell seals using geomagnetic intensity and acceleration data. PhD dissertation, The Graduate University for Advanced Studies, Sokendai, Tokyo (in Japanese)

Editorial responsibility: Peter Corkeron, Woods Hole, Massachusetts, USA
Mitani Y, Sato K, Ito S, Cameron MF, Siniff DB, Naito Y (2003) A method for reconstructing three-dimensional dive profiles of marine mammals using geomagnetic intensity data: results from two lactating Weddell seals. Polar Biol 26:311-317

Mitani Y, Watanabe Y, Sato K, Cameron MF, Naito Y (2004) 3D diving behavior of Weddell seals with respect to prey accessibility and abundance. Mar Ecol Prog Ser 281: $275-281$

Ponganis PJ, van Dam RP, Marshall G, Knower T, Levenson DH (2000) Sub-ice foraging behavior of emperor penguins. J Exp Biol 203:3275-3278

Sato K, Mitani Y, Cameron MF, Siniff DB, Naito Y (2003) Factors affecting stroking patterns and body angle in diving Weddell seals under natural conditions. J Exp Biol 206: 1461-1470

Sato K, Ponganis PJ, Habara Y, Naito Y (2005) Emperor penguins adjust swim speed according to the above-water height of ice holes through which they exit. J Exp Biol 208:2549-2554

> Sato K, Watanuki Y, Takahashi A, Miller PJO and others (2007) Stroke frequency, but not swimming speed, is related to body size in free-ranging seabirds, pinnipeds and cetaceans. Proc R Soc Lond B Biol Sci 274:471-477

Shiomi K, Sato K, Arai N, Naito Y, Ponganis PJ (in press) Distribution of emperor penguins' dive directions under the fast sea ice. In: Proc 4th Int Symp SEASTAR2000 and Asian Bio-logging Sci, Graduate School of Informatics, Kyoto University

Stoneburner DL (1982) Satellite telemetry of loggerhead sea turtle movement in the Georgia Bight. Copeia 400-408

Tanaka H, Takagi Y, Naito Y (2001) Swimming speeds and buoyancy compensation of migrating adult chum salmon Oncorhynchus keta revealed by speed/depth/acceleration data logger. J Exp Biol 204:3895-3904

Wilson RP, Wilson MP (1988) Dead reckoning - a new technique for determining penguin movements at sea. Kieler Meeresforsch 32:155-158

Wilson RP, Wilson MP, Link R, Mempel H, Adams NJ (1991) Determination of movement of African penguins Spheniscus demersus using a compass system: dead reckoning may be an alternative to telemetry. J Exp Biol 157:557-564

Wilson RP, Putz K, Peters G, Culik B, Scolaro JA, Charrassin JB, Ropert-Coudert Y (1997) Long-term attachment of transmitting and recording devices to penguins and other seabirds. Wildl Soc Bull 25:101-106

Wilson RP, Liebsch N, Davies IM, Quintana F and others (2007) All at sea with animal tracks; methodological and analytical solutions for the resolution of movement. Deep Sea Res Part II Top Stud Oceanogr 54:193-210

Zar JH (1999) Biostatistical analysis, 4th edn. Prentice-Hall, Englewood Cliffs, NJ

Submitted: March 3, 2008; Accepted: July 21, 2008

Proofs received from author(s): August 26, 2008 